\title{
The Impact of Communications Methods on Team's Productivity and Performance - Oil and Gas case study
}

\author{
AbdulGhani Gaghman \\ The Bucharest University of Economic Studies \\ abdulghanigaghman@stud.ase.ro
}

\begin{abstract}
The development of multidisciplinary team communication in oil and Gas industry is a complex area that increasingly impact on team performance and achieve the common goals. Communication is the exchange of information through actions, speech and writing or symbols. Effective team communication increases; team member's effectiveness and satisfaction because they are given the appropriate guidelines, tools and direction on how to accomplish tasks. Team members communicate via meeting, phone calls and emails. However, In the latest year's communication tool has increased significantly as the business world has gone global and more virtual communication options are introduced, (i.e. Skype, WebEx and Smartphones). The aim of this paper was to assess the team communication process and quantity the issues, in order to avoid project delays and suboptimal performance. To determine the extent to which verbal communication approach has an impact among the organization behavior and on the integration, effectiveness and efficiency of the team. This paper had examined this subject in one of the national Oil and Gas company, and concluded that team productivity and performance are highly affected by the way of the communication and the best way is to have effective face-to-face meeting with clear objective in regular basis.
\end{abstract}

Keywords. Team Communication, Oil and Gas, Face-to-Face, Effectiveness, Performance

\section{Introduction}

The effective communication depends on both sender and receivers to have the consensus about the message meaning during information transfer between them (Rollinson, 2002). The purpose of good team communication is to inform, direct and inspire members of the team. However, members have not got a comprehensive opportunity to participate and contribute to the company goal and fulfill their potential. On the other hand, most of team leaders did not have a clear methodology for resolution of issues during the meeting (Rollinson, 2002).

Despite the advanced development in communication technologies, face-to-face ( $f 2 f$ ) communication remains the most effective ways of enhancing business performance (Arvey, 2009). This view was supported by the global survey conducted by Harvard Business Review in 2009 showing that $79 \%$ said that $2 \mathrm{f}$ meetings are the most effective way to conduct business meeting and $95 \%$ said it is an essential factor in successfully building and maintaining long-term relationships.

There are several types of communication for the multidisciplinary team in oil and gas organization of which verbal communication is the most significant norm of communication 
aiming to increase the team performance and achieve the common goals. It is heavily focus on top-down one-way communication and it reinforce the role of line managers and give work purpose and relate people to the organization (Rollinson, 2002). Therefore, many researchers have concluded that face-to-face is the preferred type of communication, in the term of virtual interaction, effectiveness and more suited for the goal-oriented teams, within certain limits such as geographic distance and remote locations. However, when and where and why; should be considered making it a success form of communication with significant outcomes.

Many literatures have been examining this subject from different prospective to identify and examine the most effective and productive form of communication to fulfill organization goals and objectives. In the following section, organization behavior and problem definitions for the case study followed by the literature review enriched with alternatives discussion, optimal solution for the problem concluded, to be recommended to the company.

\section{Case Study}

The Safer Exploration \& Production Operation Company (SEPOC) has been used as a case study for this report which is Yemen's leading national oil and gas Company. $2^{\text {nd }}$ largest oil producer and the largest producer of natural gas in the country. This remarkable growth is attributed to SAFER's upstream \& midstream operations that harness the potential of Block 18 and its neighbours (SEPOC, 2009)

SEPOC has a matrix structure with dedicated development projects of which consist of 10-25 members from different discipline in each project. Each development team is goal oriented where a common goal, clear deadlines and deliverables measures are set at the commencement of project and should be accomplish following the company standards and regulations in a knowledge-sharing environment.

SEPOC communication style is top down for the directions and steering and also upward from group members to mangers. It has also a modern cubical layout work environment where, each team allocated in same cubical area aiming to enhance the physical communication within the team and with other teams. The company is characterized as highly dynamic environments, multinational, permeable boundaries and reconfigurable matrix structure with clear project tasks and time frame and clear milestone for quality assurance. So, effective and dynamic communication style is expected to be, accurate and more efficient. Company's values emphasis on the effective, open communication and reliability in a successful intercultural cooperation to provision accurate decision making (SEPOC, 2009).

The company has online platform called Community of Practice (CoP) that enable the team leader or manager to communicate, share information with teams which in the latest year used intensively instead of verbal communication. In most cases, IT-web interface creates a noise or so quite environment where divisions are created between teams and individuals and where loyalty and friendships is created in a virtual world not through web interface (Arvey, 2009).

Though the workplace design offers several meeting room with different capacity and an easy intranet webpage to book a meeting room but quit few number of teams have regular meeting (i.e. weekly or monthly). Instead, most team lack proper meeting schedules and intensively use email and ad hoc meeting if something urgent raised. Unproductive meetings structure and communication style causes more team members driven away and more alienated and became more resistance to attend meetings. This resulted in missing the outline of team's mission, lack of integration and maybe missing the scope of work of which cause conflict between team members. 
Type of communication process and its impact on team performance and productivity to fulfill the common goal; are subject in literature review to find the optimum approach of communication to be recommended to the management in the company.

\subsection{Organization Behavioural Issue:}

The communication effectiveness approaches in the organization is largely affected of which reduce the productivity and efficiency of the team and in some cases the increase the turnover rate. However, there are different forms of organizational communication available such as face-to-face, written, and electronic communication, SEPOC relies heavily on a written communication from such as emails or reports. This main Communication challenge represented in:

- Less verbal communication.

- Barriers associated with the media and channel.

- The channel of communication itself.

- Barriers associated with the message, perception and encoding.

This led to confusion, misunderstanding and unsatisfied member. Moreover has a direct impact on company objectives and goals represent in the following;

- The team unity and satisfaction and loyalty.

- Team productivity and performance

- The evaluation and instant feedback.

- The follow up of team progress and achievements

- The vision, motivation and purpose for existing

- Intercultural environment; Diversity and sharing knowledge

- Distribute the company Information and higher management messages.

\section{Literature Review}

The studies confirm that one of the key success parameters is to develop a common understanding of the parameters that control the team actions such as (tasks, achievements, obstacles, way forward, etc.). Many scholars have been examining team effectiveness from different prospective. Pentland list the main communication elements that have a direct impact on the team performance which are (Pentland, 2012):

1. Energy, size of interaction within the team members

2. Engagement, amount of energy distributed by the team members.

3. Exploration; way of involvements with other teams

The degree of success in a team will depend on how the team employed these three elements in order to achieve it upmost potential (Pentland, 2012).

Oil and Gas operation characterised as knowledge-based industry which required a sharing knowledge environment, common knowledge has a direct effect. Shared information may have a greater probability than unshared information for being encoded and recalled by individual team members (Graetz et al, 1998). Though Stryker (2012) emphasized that in the high-tech business the communication plays a critical role in accomplishing complex team tasks once it is clear and well communicated among the team members (Stryker, Santoro, 2012).

SEPOC as a big national organization enjoy the luxury of having wealth level of experiences from different nations at different level of the organization. Frigotto (2011) 
deliberate the sharing knowledge impact among teams, and concluded that team performance can be improved with the increase of knowledge variety.

Team in the company are goal oriented, the poor communication may have a negative influence when the understanding of scope is very fragmented, or team start walk away from the common goal (Frigotto, Rossi, 2012). Therefore, the physical distance may play a role in communication and the probability of face-to-face communication between two people is inversely related to the distance separating them (Stryker, Santoro, 2012); this conclusion has been well integrated in the SEPOC workplace designing where the team is located in one cubical area aiming to have more verbal communication.

\subsection{Effective Communication}

The role of team leader is to guide the team for open communication, enhance the spirit of cooperation, support team creativity and cohesiveness and manage to give equal opportunity for each member to contribute. On the other hand, the role of the team members which might aid team communication during the meetings to be more effectively and efficiently;

- Precious and clear personal contributions

- Enrich the topic with relevant information (just the right content and amount of information.)

- The integration with other discipline (Patrashkova-Volzdoska et al, 2003).

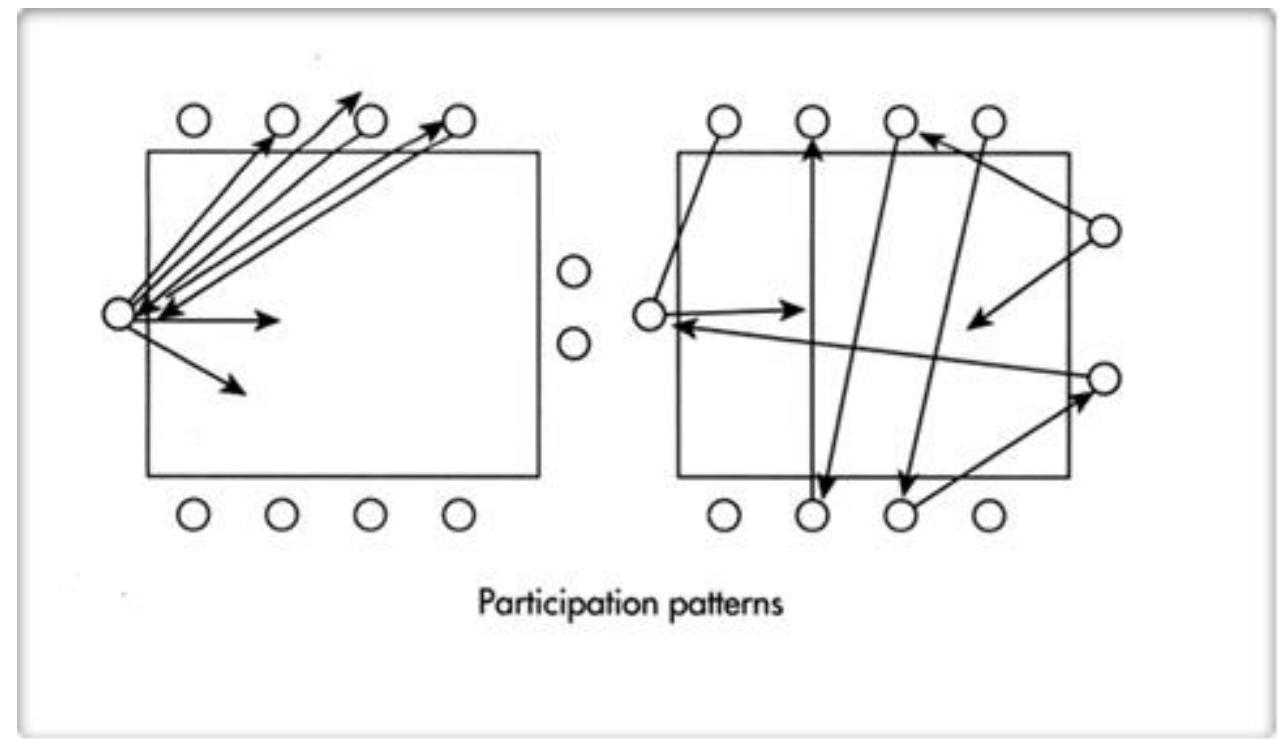

Figure 1 - Participation Pattern during a team meeting. Multi-direction communications to the right compare to one direction communications to the left (Source: Adair, 2001, p.7).

Having Individual goals is healthy, but it shouldn't affect the common goal where the individual may pay little attention to the information relevant to the team goal focusing on his target only. We notice two type of communication one has direct control by the leader as one direction or multidirectional between team members. Other teams have quite short spaces in the discussion. There is no role control individual participation to be the best, it depends on the situation, objectives and team members (Adair, 2011) see Figure (1).

Once the people are of one mind and heart, they can easily achieve their tasks or targets and doing outstanding work as teamwork (Adair, 2011). Team members should be given the opportunity to talk about any obstacles and issues and their statuses. Team leaders should set up a clear methodology for resolution of issues during the meeting and follow up 
on the issues with individual team members after the meeting (Patrashkova, McComb, 2004). However, low performance team and lack of enthusiasm with some employee to communication structure that cause lower efficiency and undesirable impact (Schippers et al, 2014).

Sharing knowledge and encourage the sharing culture may reduce the time spent by team members where they tend to hide their obstacles or insights while attempting to solve the problem on their own in the perspective of self-learning. In all businesses, effective communication skills are crucial to successfully completing and deliver the project and studies, large and small (Arvey, 2009).

\subsection{Type of communication:}

Open communication improves the effectiveness of communication aiming to reduce the obstacles faced by team members toward the success, moreover, lead to long term cohesiveness within the team. Open communication also enables timely problem solving. Implementation of problem resolution strategies is more effective when there is clear communication among team members, however, teams can use different methods to communicate.

\section{(a) Verbal communication}

Verbal communication refers to the use of sounds and language to relay a message. it considers as the most prevalent form of organizational communication (Griffin, Moorhead, 2011). In combination with nonverbal forms of communication, verbal communication acts as the primary tool for running business task and meeting or informal conversations. However, it depends on number of factors mainly the interpersonal skills such as communications skills, listening skills and clarification (Griffin, Moorhead, 2011).

Pentland (2012) concluded that, verbal or face to-face type of communication is the most valuable form of communication followed by electronic communication such as phone or videoconferences, written methods or emails is the least form of communication (Pentland, 2012). Moreover, Adair (2011) pointed out that the face-to-face communication is important since it encourage individuals to be more involved and own the conversation (Adair, 2011). It also provides a platform for more involvement, purpose, integration and form stronger team relationship Figure (2).

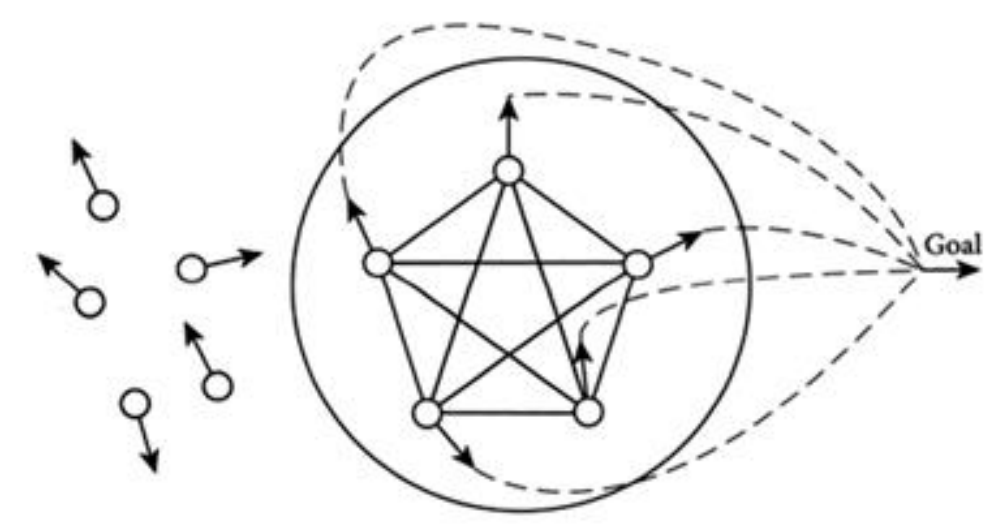

Figure 2 - Figure 2 Individuals vs. Teams Communication. (Source: Adair, 2011, p.8) 
Sharing the understanding and the scope of work or the goals lately has negative impacts on the overall team performance (Patrashkova, McComb, 2004). Moreover, working with subsurface data is associated with lots of uncertainty which may lead to high risk, this concept should effectively address during the communication to increase the chance of make better decision which can be easily delivered effectively through a proper verbal communication (Adair, 2011). Therefore, the verbal meeting helps to have the same understanding of the goal or idea in an interaction way to be able to fulfill the common team goal and avoid team failure.

\section{(i) Strengths and Weaknesses}

The increase workload has negatively impacted the individual by placing more pressure on teams, and this is currently being absorbed by stay late after working hours by many staff. Some of the team member tend to drop the meeting pretend that they are busy. Other did not see value of having a meeting due to unclear meeting agenda. The collaborating in the face-to-face settings exhibit more effective team learning behaviors than in the technology-mediated or electronic settings such as Teleconference (Andres, 2011). Dennis (2008) investigated more about the communication media and found that performance is a function of communication types the more verbal the better performance (Dennis et al, 2008). Moreover, based on Andres experiment (2002), the greater interaction quality is experienced by the face-to-face teams, also suggests that face-to-face communication is better suited to the implementation of the group member support and group well-being functions delineated in McGrath's TIP theory (1990) (Andres, 2002).

In the SEPOC daily activities the discussion and follow up on the plan executions are crucial where it needs an efficient, rapid and more verbal communication to reach to a realistic decisions in short time, the magnitude of wrong decision may have a catastrophic impact on the team. A prompt update, feedback or decision outcomes should be shared across all team members and no better way of conveying the message other than face-to-face communication to avoid any misunderstanding or decoding the message or email wrongly (Dennis et al, 2008).

Latest survey done by Gaghman (2020) highlighted that, organize periodically interactive workshops, active community of practice (CoP.) and increase the number of short assignments considered to be the most effective method for knowledge sharing and retention in oil and gas business (Gaghman, 2020).

The time consuming considered as key weaknesses for face-to-face (f2 $f$ ) communication. In some cases, more meetings drain the time and end up with no time for the members to do their technical works, This definitely harm the team productivity, also the more member involved in meetings the more lack of over all productivity and harm the project budget where 2 hours meeting cost $>$ USD 5000. Deviation from the agenda or lack of one altogether may cause running the meeting longer than it should. Also meeting requires an actual physical place for people to meet to exchange information (Stryker, Santoro, 2012).

\section{(b) Virtual communication method}

Video conferencing, telephone conferences, instant messaging, webinars and webcasts are other communication methods that teams can use to facilitate interaction. Long distance communication has become keys to the success of many organizations and nowadays a remote workers and virtual teams are quickly becoming the norm these days. 


\section{(i) Strengths and Weaknesses}

Like face-to-face conversation, electronic communication is interactive, but like document preparation electronic communication is typically edited (Desanctis, Monge, 1998). As a result, behavior in electronic communication settings takes on characteristics of both document writing and informal speech. Physical contact in the electronic communication may negatively affect the understanding of the message and reduce the feedback (Desanctis, Monge, 1998). On the other hand, Marshall and Novick (1995), stated that there is no clear impact of absent of physical contact on the quality of the message or the feedback (Marshall, Novick, 1995).

Define the meeting context in advance is crucial to have a proper communication and clear agenda but Desanctis (2006) stress on the form of electronic communication are more suited for the pre-defined context comparing to face-to-face communication (Desanctis, Monge, 1998). In contrast, Graetz (1998) argued that for the high-tech or sharing knowledge firms the teleconferencing is the best form of problem-solving communication (Graetz et al, 1998). In the other hand Graetz introduced the emotional elements where individuals may experience discomfort while discussion and may stay clam which reduce the contribution by the team members and the productivity of the team (Graetz et al, 1998).

Andres (2002) pointed out that, decision-making process and the quality of final decision are closely related to the use of electronic communication (Andres, 2002). The task type (whether a production task or decision making) as a factor that could play a signification part in the determining the influence of communication technology on team members. In SEPOC effective collaboration requires sharing knowledge or information, rapid integration of team effort, and decision-making type of meeting needed more verbal communication however, electronic communication may be needed as well to establish contact for the remote (rig/ field) sites.

\section{(c) Written communication}

Team documents serve as a written record of the different phases of a project. Written communication can be in the form of email, final report, collaborative documents and presentations and status reports. In this discussion more focused about the form of email, where we operate in a world of inboxes (Griffin, Moorhead, 2011).

\section{(i) Strengths and Weaknesses}

Non-verbal or written communications simply miss the human elements of nonverbal communication such as facial expressions and body language, and the environmental elements (i.e. furniture, office and buildings) which may convey messages (Griffin, Moorhead, 2011).

Recently, Email consider the main and highly effective form of business communication tool. If used correctly, it can be an excellent medium for quick message exchange (Derks, Bakker, 2010). Email is stored automatically, can be accessed at any time and is easy to compose and send. Unfortunately, there are, besides advantages also side effects. This ease of access can trigger overuse by sending many email to every recipient, too much information communicated could be far more detrimental than too little information (Patrashkova, McComb, 2004).

The impact of e-mail on a regular workday is inherent on differences between e-mail and face-to-face communication. McKenna and Bargh (2000) summarize these differences as following: 
1. In emails the physical distance has no issue, and the physical appearance is absent in email,

2. The time is two-folded, it can be an influential cue in interpreting a message.

3. Finally, it is easier to be anonymous while communicating on the internet.

Email is certainly less personal than face-to-face communication. It has a negative impact on the social interaction and might lead to less relationship building in the workplace. Misunderstandings are commonplace in written communication simply because the recipient cannot read the writer's tone and expression, and therefore is left to interpretation. Consider that even though email can be quite informal, it is also a permanent record and should be treated carefully (McKenna, Bargh, 2000).

In reality employees complain about the huge amounts of e-mail they receive on a regular day; the pressure of the expectations to answer these e-mails within a day and; some time the follow the email with a phone call to double check and emphasize on respond. Furthermore, the team members complain about information overload, especially when the received information was not requested.

\section{Recommendation}

The communication in Oil and Gas organization should be clear, rapid, and precise. this type of communication can be easily delivered through a verbal communication. Despite the verbal meeting weaknesses, SEPOC should encourage team leaders to establish an effective regular verbal team meeting; type of meeting and media will be depending on the team geographical distribution, which enhance the collaboration and integration between team member to achieve the common goals.

Enable team members for more engagement, interaction and exploration by implementing an integrated effective verbal communication (Pentland, 2012). Team leaders on the other hand should approach these with clear set of methodology to record, resolve and evaluate those risen concerns (Patrashkova. McComb, 2004).

To effectively improve team communication, members have to be encouraged, inspired, to participate in an open communication that opened a wide horizon with mutual benefit for both individuals and organization.

Although emails or web interface (CoP) cannot and should not replace all face-toface communication and others forms of communication, internal email usage can cover many areas within the business. Internal emails can function as an effective communication for sharing basic information, such as company news, schedules, and paper use as guidelines or security precautions.

In Summary the recommendation as following:

Organize face-to-face weekly meeting for 2 hours with the team members.

More effective meeting (Leading, follow up, participation, feedback).

Use the email and the intranet website (CoP) for the common purposes.

Improve the interpersonal communication skills.

\section{Conclusion}

This paper discusses different type of communications and found that the $\mathrm{f} 2 \mathrm{f}$ and interactive discussion is the foundation of communications of which need to establish a proper foundation to enables efficient and more productive communications. Implementation of sharing knowledge, making decision progress evaluation and feedback for improvement is more effective when there is clear communication among team members. The relationship 
between the various forms of communication, team composition and structure, type of goals will have significant implications on the team productivity and performance.

Verbal communication mainly is perceived as the main form of communication, more effective and efficient to achieve team objectives. Mainly because face-to-face is more virtual interaction, more engagement, drive participation, and the richest media compare to the other forms of communications.

SEPOC has a modern infrastructure with well design workplace that give the needed foundation to stimulate an effective verbal communication. However, a clear objectives on this front is urgently needed since the existing goals are misunderstood and sometimes ignored. Company to start implement more interactive approach with regular face-to-face meeting to minimize and eventual eliminate the failures associated with decision making and sharing information (Schippers et al, 2014), and this could be be done through open communication channels and improve the communication skills, evaluation the conclusions and close out the feedbacks as part of effective communication.

\section{Reference}

[1] Rollinson D., (2002), Organizational Behaviour and Analysis, An Integrated Approach, 2nd Edition Prentice Hall, UK, p.611.

[2] Arvey, R. D. (2009). Why Face-to-face Business Meetings Matter. Business School, National University of Singapore.

[3] SEPOC. (2014) about the company [online] available from http://www.sepocye.com/ [Accessed: 22nd December 2014].

[4] Pentland, A. (2012). The new science of building great teams. Harvard Business Review, 90(4), 60-69.

[5] Graetz, K. A., Boyle, E. S., Kimble, C. E., Thompson, P., \& Garloch, J. L. (1998). Information sharing in face-to-face, teleconferencing, and electronic chat groups. Small Group Research, 29(6), 714-743.

[6] Stryker, J. B., \& Santoro, M. D. (2012). Facilitating face-to-face communication in hightech teams. Research-Technology Management, 55(1), 51-56.

[7] Frigotto, M. L., \& Rossi, A. (2012). Diversity and Communication in Teams: Improving Problem-Solving or Creating Confusion?. Group Decision and Negotiation, 21(6), 791820.

[8] Patrashkova-Volzdoska, R. R., McComb, S. A., Green, S. G., \& Compton, W. D. (2003). Examining a curvilinear relationship between communication frequency and team performance in cross-functional project teams. Engineering Management, IEEE Transactions on, 50(3), 262-269.

[9] Adair, J. (2011). Effective Team building: How to make a winning team. Pan Macmillan. [Accessed; 20 December 2014].

[10] Patrashkova, R. R., \& McComb, S. A. (2004). Exploring why more communication is not better: insights from a computational model of cross-functional teams. Journal of Engineering and Technology Management, 21(1), 83-114.

[11] Schippers, M. C., Edmondson, A. C., \& West, M. A. (2014). Team reflexivity as an antidote to team information-processing failures. Small Group Research, 45(6), 731-769.

[12] Griffin, R., \& Moorhead, G. (2011). Organizational behavior. Cengage Learning.

[13]Derks, D., \& Bakker, A. B. (2010). The impact of e-mail communication on organizational life. Cyberpsychology: Journal of Psychosocial Research on Cyberspace, 4(1).

[14] Andres, H. (2011). Collaborative Technology and Team -Based Problem Solving. 
[15]Dennis, A. R., Fuller, R. M., \& Valacich, J. S. (2008). Media, tasks, and communication processes: A theory of media synchronicity. MIS quarterly, 32(3), 575-600.

[16] Andres, H. P. (2002). A comparison of face-to-face and virtual software development teams. Team Performance Management, 8(1/2), 39-48.

[17] Gaghman, A.A., 2020. The Impact of Knowledge Behavioural Factors on Tacit Knowledge Retention: Empirical Study in Oil and Gas Industry. KnE Social Sciences, pp.34-53.

[18] Desanctis, G., \& Monge, P. (1998). Communication processes for virtual organizations. Journal of Computer-Mediated Communication, 3(4), 0-0.

[19] Marshall, C. R., \& Novick, D. G. (1995). Conversational effectiveness in multimedia communications. Information Technology \& People, 8(1), 54-79.

[20] McKenna, K. Y., \& Bargh, J. A. (2000). Plan 9 from cyberspace: The implications of the Internet for personality and social psychology. Personality and social psychology review, $4(1), 57-75$. 